\title{
LITERATURA DE REVOLUCIÓN Y LITERATURA REVOLUCIONARIA: DOS NOVELAS CORTAS
}

LAS MANOS DE MAMÁ DE NELLIE CAMPOBELLO Y PROSERPINA RESCATADA DE JAIME TORRES BODET

\section{Gabriel M. Enríquez Hernández}

Instituto de Investigaciones Filológicas, UNAM

Centro de Estudios Literarios

gmenriquez@gmail.com

Resumen: El presente trabajo aborda dos novelas cortas de los años treinta en México. Por una parte, muestra el carácter híbrido, en el caso de la novela Las manos de mamá, de Nellie Campobello; por la otra, describe el recurso de la metáfora narrativa que Torres Bodet emplea en Proserpina rescatada, mecanismo que proviene de Marcel Proust y que se distancia de los comúnmente asociados con la novela lírica.

Palabras clave: novela lírica, Contemporáneos, novela de la Revolución mexicana, novela corta, hibridez narrativa.

\section{LITERATURE OF REVOLUTION AND REVOLUTIONARY LITERATURE: TWO SHORT NOVELS}

LAS MANOS DE MAMÁ BY NELLIE CAMPOBELLO AND PROSERPINA RESCATADA BY JAIME TORRES BODET

\begin{abstract}
The present work approaches two short novels of the thirties in Mexico. On the one hand, it shows the hybrid character, in the case of Campobello's short novel Las manos de mamá, and, consequently, the difficulty of establishing a genre in the traditional way; on the other hand, the resource of the narrative metaphor that Torres Bodet uses in Proserpina rescatada, a mechanism that comes from Marcel Proust and that distances itself from those commonly associated with the lyrical novel.
\end{abstract}

Keywords: lyric novel, Contemporáneos, novel of the Mexican Revolution, short novel, narrative hybridity.

\section{DOI: https://doi.org/10.24029/lejana.2020.13.426}

Recibido: el 24 de noviembre de 2018

Aceptado: el 1 de marzo de 2019

Publicado: el 19 de febrero de 2020 


\section{Del cuadro de costumbres al poema en prosa: Las manos de mamá}

Es ampliamente conocido el hecho de que hacia fines de 1924 y principios de 1925 se llevó a cabo la polémica que encumbró a un desconocido novelista que no pertenecía al campo cultural de la Ciudad de México, y que en aquellos tiempos se desempeñaba como médico de dispensario del populoso barrio de Tepito, Mariano Azuela. Al proponer el encumbramiento de la Revolución mexicana, heredera del "impulso creador de la Independencia y la voluntad renovadora de la Reforma" (Avechuco, 2017: 89), el Estado mexicano pretendía darle sentido a los complejos sucesos que la gente vivía, así como justificar y legitimar el accionar de los revolucionarios, pero, sobre todo, afianzar su poder político. De aquí la necesidad de integrar "una ideología que explicase, justificase y cimentase el nuevo Estado mexicano" (Meyer citado por García, 1999: 27). A causa de diversos intereses políticos, entre otros la visión unitaria de los movimientos armados de la Revolución, Emiliano Zapata, Ricardo Flores Magón, Felipe Ángeles, y algunos más, fueron ingresados en la lista de inmortales; Francisco Villa, no. Al Centauro del Norte se le atribuyeron prácticamente todos los excesos del movimiento armado (Avechuco, 2017: 71-89). ${ }^{1}$

Era evidente que, aun antes de la ahora célebre polémica, desde principios de noviembre de 1924 existía interés por colocar a Mariano Azuela como modelo de escritor, lo mismo nuestro y comprometido que viril. Al menos es lo que permiten advertir las palabras de Febronio Ortega, Arqueles Vela y Carlos Noriega Hope, este último director del suplemento cultural del diario que impulsó el debate, El Universal Ilustrado, allí publicadas el 24 de noviembre: "La revolución tiene un gran pintor, Diego Rivera. Un gran poeta, Maples Arce. Un futuro gran novelista: Mariano Azuela, cuando escriba la novela de la revolución" (Corral Rigan, 45). La dicotomía literatura afeminada-literatura viril, propuesta por Julio Jiménez Rueda ${ }^{2}$ en diciembre de ese año, contribuyó a afianzar la política cultural del Estado mexicano. Francisco Monterde fue quien propuso a Mariano Azuela como el "novelista mexicano de la revolución" (1924: 3). Muy pronto, el 29 de enero de 1925 se publicó en las páginas de "La novela semanal", suplemento del diario, la primera de cinco entregas de Los de abajo, novela que inaugura el subgénero de la novela de la revolución, pero sin el subtítulo de la primera edición publicada en El Paso, Texas en 1915, hasta antes de la polémica desconocida, a saber, Cuadros y escenas de la revolución actual.

Nellie Campobello (María Francisca Moya Luna, Durango, 1900), publicó Cartucho, relatos de la lucha en el Norte de México en 1931, seis años después de la polémica. Este título le permitió ingresar a la lista de novelistas de la Revolución mexicana, si bien su obra en los primeros años fue opacada por esa especie de fresco monumental que ofrecen narradores como el propio Azuela, Martín Luis Guzmán o José Vasconcelos.

Nellie Campobello nos comunicó dos de sus intenciones al escribir su obra. En primer lugar, buscaba realizar una literatura más vivida que leída; es decir, una cuyo basamento se

\footnotetext{
${ }^{1}$ Según este autor, tres son las razones por las que Villa no ingresó al álbum familiar revolucionario de aquellos años: la primera tiene que ver con la rivalidad con Álvaro Obregón, principal promotor de la institucionalización; la segunda, con la carencia de elementos ideológicos para integrar al discurso oficial; y la tercera, con el poder de convocatoria del caudillo del Norte (Avechuco, 2017: 71).

${ }^{2}$ Escribía Jiménez Rueda: "ya no somos gallardos, altivos, toscos [porque] ahora suele encontrarse el éxito [literario] más que en los puntos de la pluma, en las complicadas artes del tocador" (cito por Ródenas, 2004: XXV).
} 
configurara con fuertes tintes autobiográficos y memorísticos. En segundo, una en la que expresara su necesidad de contar la verdad. Y su verdad consiste en mostrar que Francisco Villa no merece el lugar de bárbaro que la novela de la revolución y la historia oficial le habían destinado. Con la aspiración de alcanzar este empeño, Campobello eligió a un narrador infantil puesto que, como Begoña Pulido ha perfilado ya con una frase popular, "los niños dicen la verdad" (2011: 42). El afán de alcanzar un alto grado de veracidad en su relato fue expresado por la propia autora en el prólogo que escribiera para Mis libros:

Latente la inquietud de mi espíritu, amante de la verdad y la justicia, humanamente hablando, me vi en la necesidad de escribir. Sabía que el ambiente en que yo vivía no era propicio a mi deseo [...] Busqué la forma de poder decir, pero para hacerlo necesitaba una voz, y fui hacia ella. Era la única que podía dar el tono, la única autorizada: era la voz de mi niñez. (Campobello, 1960: 12)

Una vez obtenida la voz, requería encontrar la forma y el tono. Razones artísticas e históricas guiaron su selección. Begoña Pulido ha sostenido que en la raíz del estilo poético de Campobello se encuentra el contraste, "la distancia entre lo que se dice y cómo se dice", un sistema metafórico más próximo a la vanguardia que al realismo y una estructura cerrada, autónoma, es decir, textos redondos que pueden ser leídos de manera independiente (2011: 39). Esta disposición creativa, el afán de contraste, provoca ese estado de indefensión en el lector ante una niña que narra escenas atroces: muertos que se convierten en juguetes, tripas de cadáveres transportadas como trofeo por la calle, pedazos de cabeza, orejas, brazos desprendidos de su cuerpo, etcétera. Aunado a esta intención artística, razones históricas determinaban el hecho de que la narradora contemplara estos asuntos con bastante normalidad, con indiferencia incluso. Refiere Avechuco, basado en Aguilar Camín y Katz (2017:85), que la zona Norte de principios del siglo XX en nuestro país mantenía la tradición de autodefensa, pues sus habitantes descendían de aquellas sociedades militares de frontera que en el siglo XIX luchaban por mantener el territorio ante los ataques de las tribus nómadas indias. La autodefensa refuerza los vínculos de orgullo comunitario pues, en palabras de Campobello, el hombre de la sierra duranguense resulta "verdadero ejemplar de una raza de ascendencia guerrera" (1960: 194). Consecuencia de esta concepción es que para la novelista de la revolución Francisco Villa resultara "guerrero genial” (Campobello, 1960: 14).

Ahora bien, la determinación del carácter genérico de las novelas de Campobello es un aspecto sobre el que los críticos no han logrado ponerse de acuerdo. En un rápido recuento bibliográfico he encontrado más de una docena de géneros y subgéneros, literarios o no: imágenes, cuadros, viñetas, fragmentos, cuentos, relatos, estampas, fotografías, postales, bocetos, retratos orales, crónicas, cartucho, collage, balazo y poema en prosa.

Antonio Castro Leal, que como se recordará incluyó las novelas de Campobello en sus tomos de La novela de la Revolución mexicana, al referirse a ellas, empleó un término conocido entre los escritores de principio del siglo XX: cuadros (téngase en cuenta que la novela de Azuela, Los de abajo, lleva por subtítulo Cuadros y escenas de la revolución actual) (1960: 923). Desde mi punto de vista, Tanya Weimer, aunque no profundiza en el asunto, precisó con mayor justeza el asunto genérico al establecer que "la obra de Campobello participa de la tradición decimonónica de los cuadros de costumbres a la vez que se inserta en el movimiento de vanguardias" (2010: 106). 
Como ha señalado José Manuel Cuesta, la palabra cuadro se relaciona con la francesa tableau. Su sentido, literariamente hablando, es pictórico, pues el término está destinado a resaltar de manera particular el realismo mimético o naturalista de una escena. El mismo autor nos recuerda que el inventor de este modo de concebir la literatura fue Louis-Sébastien Mercier quien, con sus seis volúmenes del Tableau de Paris, publicados entre 1781 y 1788, pretendía establecer "la fisionomía moral de esta gigantesca capital". Los Cuadros de Mercier, que buscaban ensamblar todas las pequeñas costumbres de la ciudad parisina para construir un cuadro del siglo, dieron origen a los cuadros de costumbres, caracterizados por cuatro aspectos: 1) la representación de la vida civil, es decir, la pintura de la vida burguesa, la clase media; 2) la veracidad; los pintores costumbristas buscaban realizar una obra exacta de las circunstancias que veían, tal y como las veían, sin juzgar; 3) la particularidad de las circunstancias enteramente locales pues los artistas estaban conscientes de que la sociedad de cada país es distinta; incluso la perspectiva de mediodía no es la misma que la vespertina; 4) la vinculación con la historia. La imagen de cada cuadro tenía que ser veraz porque estaba destinada a convertirse en un documento histórico (Escobar, 2005).

Si Campobello había logrado con Cartucho transmitir, basada en el modelo del cual partía, el cuadro de costumbres, esa especie de microhistoria como la ha etiquetado Begoña Pulido, vale decir, el modo de vivir la revolución de la gente del Norte, y transmitir su verdad sobre los centauros de la División del Norte, gente sencilla acostumbrada a la vida combativa, así como metaforizar con la fragmentación de los cuerpos tirados frente a la casa de su narradora un movimiento armado igualmente quebrantado, ¿qué buscaba con la escritura de Las manos de mamá (1937), un título intimista, distante del explosivo cartucho?

Quiero señalar que, en principio, Campobello no se detuvo en el género decimonónico pues lo dotó de una imagen dinámica y con una buena dosis de sentido poético, vinculado este último, además de la imagen, con la sugerencia. El texto de Campobello sugiere tanto como describe. Ya Max Parra ha trazado la asimilación de la fotografía que se observa en Cartucho, recurso extraordinario para captar "la rapidez de los sucesos y la fuerza de los estados emotivos" (2017: 349), así como la vinculación que esta mantiene con la modernidad, lo que equivale a "pensar la modernidad en términos fotográficos, es decir, de fragmentos visuales únicos e irrepetibles, que el ser humano registra y asimila mediante procesos conscientes e inconscientes" (2017: 347). Asimismo, Parra ha señalado el auge que la imagen tuvo en las vanguardias literarias latinoamericanas, "entre ellos los estridentistas mexicanos, en cuya órbita se llegó a mover Campobello" (íd.). Es difícil, después de estas caracterizaciones de la imagen en Cartucho, no advertir su recurrencia en Las manos de mamá: "La tierra es roja, las banquetas desdentadas, los focos cabezas de cerillos" (Campobello, 2016: 173); "Mamá, vuelva su cabeza. Sonría como entonces, girando en el viento como amapola roja que se va deshojando" (178); "La máquina [de coser], muñeca tosca, se quedaba abandonada, las bastillas arrugadas estrangulaban, a veces la rueda, brillante como anillo de estrellas" (193). El cuadro que abre la novela, costumbrista lo mismo que poético, más allá de trazar la imagen de la madre, se erige en estandarte de una cultura que fundamenta su identidad en una naturaleza agreste y sencilla; contiene, además, uno de los fundamentos ideológicos manejados por Campobello en la obra de 1937, a saber, la defensa de los valores de una comunidad sustentada, a diferencia de la del centro y sur del país, por el trigo. 


\section{ASÍ ERA ELLA...}

Esbelta como las flores de la sierra cuando danzan mecidas por el viento.

Su perfume se aspira junto a los madroños vírgenes, allá donde la luz se abre entera.

Su forma se percibe a la caída del sol en la falda de la montaña.

Era como las flores de maíz no cortadas y en el mismo instante en que las besa el Sol.

Un himno, un amanecer toda Ella era. Los trigales se reflejaban en sus ojos, cuando sus manos, en el trabajo, se apretaban sobre las espigas doradas y formaban ramilletes que se volvían tortillas húmedas de lágrimas. (Campobello, 2016: 173)

Ciertamente, en las líneas precedentes y en la novela, también hay una alusión al maíz; pero, en este caso, la referencia a las "flores de maíz no cortadas", además de indicar la situación virginal del campo, señala la condición de planta monoica que es el maíz, o sea, aquella que contiene las unidades reproductivas masculinas y femeninas a la vez. La comparación de la madre con las flores de maíz se relaciona consecuentemente con el hecho de que además de desempeñar su rol materno, tuvo que asumir el del padre. La presencia del trigo, en cambio, se establece como alimento básico de la familia Moya Luna, tanto en el texto precedente como en el resto de los cuadros: "Nuestra realidad era una tortilla redonda de harina, una taza ancha de café" (Campobello, 2016: 178). Del contacto con la naturaleza se desprende uno de los tópicos de la literatura universal, la alabanza de aldea y el menosprecio de corte, y muy posiblemente el origen de su seudónimo: Campobello. Uno de los mayores valores que la escritora duranguense enarbola en su novela es la libertad, concepto que mejor se adquiere en contacto con la naturaleza, pues esta, además, proporciona salud. La libertad y la sencillez de la gente del norte del país están presentes en la decisión del abuelo de cambiar una casa por un poco de tabaco y alcohol.

En esta obra persisten las imágenes de una revolución que, sin ser nunca del todo expresamente descrita, se erige como trasfondo cotidiano del personaje principal y en la que, de manera específica, subsiste al lado de la visión de los correligionarios del Centauro del Norte, personificada en la estampa de Rafael Galán. No obstante, el contraste es, por decir lo menos, arriesgado: la imagen de Rafael Galán, que en el apellido ostenta su virtud, resulta edulcorado al lado del siguiente cuadro que tiene más cabida al lado de los de Cartucho. En él se puede apreciar el movimiento que toda la escena contiene. Esto lo distancia de la fotografía y lo coloca más cercano a las breves reproducciones que los asistentes de los hermanos Lumiére llevaron a cabo durante el porfiriato en la calle de Plateros; con una contundente diferencia, la imagen poética con la que se cierra el cuadro. La inocente crudeza, el horror estético con que el cuadro entero se traza parece emanado de Las flores del mal. No sería descabellado proponer la presencia de la tradición poética de Occidente, a la par de la natural visión de una niña descendiente de guerreros en Las manos de mamá. Me refiero al poema en prosa, de origen alemán; Novalis, puesto en circulación por Baudelaire (como sabemos, es el poeta alemán, con sus Himnos a la noche, quien introduce el poema en prosa en la literatura occidental).

Jacinto fue a caer al lado izquierdo del puente, yendo de aquí para allá. Testereando contaban - había dado sus últimos pasos, como cuando, niño de un año, empezaba a andar. Torpemente alcanzaría un pedazo de tabla, pero un pedazo grande de su cabeza ya lo había dejado atrás, tirado como algo que se abandona, porque ya no se necesita, y se vuelve un 
estorbo. Se arrugó blandamente. Había ido soltando sus pensamientos sobre las tablas rojas donde hizo su última danza, y de pronto, su carne morena, arrugada por los balazos, se extendió de largo a largo. Jacinto se quedó dando un abrazo al cielo. (Campobello 2016: 194195).

Finalmente, y más allá de la descripción del espacio doméstico en el que las mujeres del norte viven la revolución - cosen, hacen tortillas, cuidan el hogar y a los hijos mientras cantan y ríen-, detrás de este inocente título, Las manos de mamá, se encuentra un reivindicación de la autora para mujeres como su madre: en ellas radica el verdadero heroísmo de la contienda porque son ellas quienes logran ejecutar su destino vital, circunstancia que no sucede con los militares, sean estos villistas o carrancistas. Una vez dentro de la revolución, no te puedes detener (recuérdese el ejemplo que Demetrio Macías pone a su mujer: como una piedra que rueda hacia la cañada así es la vida de un revolucionario). En una primera lectura Las manos de mamá se advierten como protectoras y proveedoras de sustento y vestido para sus hijos; pero hacia el final de la narración, en el par de líneas que cierra el libro, encontramos una extensión del círculo doméstico al que habían sido circunscritas: "Tarde roja, prolongada en las venas de sus manos, las que rompieron la blusa para encontrar su dios..." (2006: 202). La línea nos remite a la sección ocho, titulado precisamente "Su dios". Cabe recordar que la novela contiene dieciséis secciones, puesto que la última es una carta dirigida a la madre. Esto podría mostrar la importancia central que tiene. Lo que aquí se refiere de una manera indeterminada, brumosa, indirecta, es un juicio donde la mamá defiende la custodia de sus hijos. No se dice el porqué la madre se ve prácticamente impedida de conservarlos. Una persona le dice que solo Dios podrá salvarla. Ante las reiteradas determinaciones del juez, "Es la ley", ella responde con su bebé entre brazos: "Son mis hijos". Antes de la pérdida irreparable que se cierne sobre ella, exhibe al juez su blusa rota, prueba de una violación. El juez la exonera al tiempo que ella exclama: "Así es la ley... A veces dice que los hijos nacidos de la propia carne no son nuestros, pero una rotura hecha a tiempo en la blusa desbarata las ochocientas hojas donde lo afirman" (Campobello, 2016: 186). La lectura de Doris Meyer e Irene Matthews aclaró esta escena: los padres del esposo muerto reclaman la custodia de los nietos por la hija ilegítima de un año que carga entre brazos. Pero la mamá, en su defensa, alude violación (citado por Pratt, 172). Este hecho revela no solo la integración de la mujer a la ciudadanía, desproporcionadamente masculina en los años de la Revolución, sino un aspecto de carácter pedagógico esbozado por Nellie Campobello en Mis libros:

Amar a nuestro pueblo es enseñarle el abecedario, orientarlo hacia las cosas bellas, por ejemplo, hacia el respeto a la vida, a su propia vida, y, claro está, a la vida de los demás; enseñarle cuáles son sus derechos y cómo conquistar estos derechos; en fin, enseñarle con la verdad, con el ejemplo; ejemplo que nos han legado los grandes mexicanos, esos ilustres mexicanos a los cuales no se les hace justicia [...]. (1960: 29)

La novela de Nellie Campobello resulta, de esta manera, revolucionaria por la forma, mezcla de tradición y vanguardia, así como por sus contenidos, pues rompe con la visión de una revolución monolítica, uniforme, al ser expresión de un grupo marginal, descentralizado, con una diversidad étnica y cultural que la visión estatal tardaría años en reconocer. Asimismo, 
destruye la visión disyuntiva entre literatura de revolución y literatura revolucionaria, pues en Las manos de mamá ambas propuestas estéticas cohabitan de manera natural.

Finalmente, a mi juicio los cuadros, de origen costumbrista, que como ha señalado la crítica, se pueden leer de manera independiente, narran una historia, pero es justamente la sugerencia construida con base en un aparato poético la que obliga al lector a procesar lo que apenas se alude, aspecto que permite una mayor concentración diegética, pero, al mismo tiempo puede lograr la expansión y la profundidad de un solo personaje, el juego dinámico que Luis Arturo Ramos propone como característico de la novela corta (2011: 9-33). Además, en el texto se evidencia la tensión genérica entre prosa y poesía que, ciertamente, se ha llevado a cabo a lo largo de los siglos, hasta arribar al poema en prosa. Los cuadros poema, colocados en serie, alimentados por la memoria, conforman una singularidad genérica de este tipo de escritura híbrida cuanto fronteriza.

\section{La metáfora narrativa en Proserpina rescatada}

Aquel año de la polémica de 1925 en el que se tildó de femeninos a los Contemporáneos ${ }^{3}$ conjunta una serie de acontecimientos decisivos para que este grupo de escritores se planteara como proyecto común escribir novelas. Es el año de la publicación de La deshumanización del arte e Ideas sobre la novela, de José Ortega y Gasset. Es también el año en que Jaime Torres Bodet planea llevar a cabo una revista, como la Revista de Occidente, y en el que surge su nombre Contemporáneos. Asimismo, es el año en que se están terminando de editar las novelas de la colección Nova Novarum, apéndice de la publicación periódica de Ortega y Gasset, que saldrán publicadas al año siguiente.

El programa colectivo sostenía el propósito de realizar una literatura con doble derrotero, pero con idéntico fin: por una parte, rechazar la literatura de retórica nacionalista que se estaba identificando con la Revolución y con los propósitos del Estado, empeñada en reflejar lo mexicano (el folclore, lo popular, el costumbrismo, el mundo campesino), y, por otra, escribir una literatura enfocada en sus propios intereses y temas; moderna, universal, antes que mexicana y, en palabras de Bernardo Ortiz de Montellano, de una literatura revolucionaria, antes que de revolución (Sheridan, 1985: 385; García, 1999: 91). ${ }^{4}$ Los Contemporáneos rechazaban, asimismo, las ideas estéticas en torno a la correlación que se establecía entre la novela de la Revolución y el realismo como única opción legítima para toda forma de arte, así como la convicción de que el arte nuevo era deshumanizado. ${ }^{5}$

\footnotetext{
${ }^{3}$ Maples Arce, al parecer, fue el primero que los tildó de afeminados, "maricones y pederastas". El propio Carlos Pellicer hacía eco sutil de esta caracterización: "Es curioso: en el país de la Muerte y de los hombres muy hombres, la poesía y la crítica actuales saben a bizcochito francés" (Ródenas 2004: XXX).

${ }^{4}$ Es importante recordar, como lo han hecho anteriormente Sheridan (1982: 8) y García (1999: 91) que los Contemporáneos rechazaban el proyecto institucional de la novela de la Revolución mexicana y no al escritor canonizado por ella, Mariano Azuela.

${ }^{5}$ Guillermo Sheridan ha sintetizado la postura antideshumanización de la siguiente manera: "No podían soportar la proposición de que el refinamiento estético implicara una deshumanización, de que el anti-represtacionismo en pintura, la atonalidad en música, el verso libre en poesía o el monólogo interior en prosa llevaran a la pérdida de lo humano, de los «elementos demasiado humanos del realismo romántico o del naturalismo»" (1982: 9). Domingo Ródenas, por otra parte, ha señalado que al menos Villaurrutia, Cuesta y Owen seguían a André Gide en su rechazo al nacionalismo: "Gide que en 1987 había desacreditado a Barrès debido a su limitada visión francocéntrica y su mercenaria defensa del nacionalismo francés” (2004: XXVIII). Esto era lo que expresaba Torres Bodet en su ensayo "Reflexiones en torno a la novela": "El siglo XIX parece haberse complacido en
} 
Si bien el nombre de novela lírica con el que se ha identificado la obra narrativa del grupo se vincula con las novelas publicadas en España, algunas bajo el sello de la Revista de Occidente, habría que señalar que también lo hace, y de una manera más contundente, con el carácter de poetas que tienen la mayor parte del grupo. Incluso se ha llegado a señalar una especie de continuidad entre su narrativa y su poesía. Rosa García, por ejemplo, sostiene en su libro que Dama de corazones es un ejercicio de preparación para llegar a los "Nocturnos" en Xavier Villaurrutia (1999: 22). Fiel reflejo del agotamiento que tenía la narrativa decimonónica realista para los Contemporáneos resultó el juicio que emitiera Salazar Mallén, referido por Sheridan: "Para Salazar Mallén estaba claro que la novela no podía ya, como pedía Ortega, seguirse deteniendo "en esas dos estaciones: el argumento y el protagonista" pues era mejor que "la novela se hubiera apeado en un nuevo andén: la poesía, que burló hábilmente las aduanas del realismo para refugiarse en las fronteras de la lírica” (1982: 9).

Las palabras de Salazar Mallén pueden identificarse claramente con algunos de los conceptos de la novela lírica española estudiada, entre otros, por Darío Villanueva. El aniquilamiento de la trama había conducido a los narradores españoles a sustituir la línea argumental por la articulación del texto en unidades mínimas, concebida la obra como una "suma de momentos felices, de «epifanías» en cuya óptima plasmación la intensidad estilística es fundamental" (2009: 165). Resultaba lógico que los textos demandaran capítulos muy breves. Para Villanueva, el carácter de una trama que no progresa provocaba, aunado a la intensidad estilística, idéntica sensación a la experimentada ante la lectura de un poema. El lenguaje, consecuentemente, pasaba de ser un medio para convertirse en un fin (2009: 164).

Guillermo Sheridan definió, a mi parecer, la sustitución de la trama por la metáfora, decisiva relación que cohabita en estas novelas, con una fórmula poética: "El signo más evidente, más externo de esta idea de la prosa (patente en Owen, Villaurrutia y Torres Bodet, principalmente) es la importancia de la metáfora, ya no como ingrediente sino como el impulso mismo del texto [...] Desplazar el impulso metonímico — aquél que se significa en el «y luego» o el «y entonces»— por el metafórico — el que se significa por el «como»— puede considerarse el cambio formal más susceptible" (1982: 10). Un ejemplo claro de la fórmula expresada por Sheridan lo encontramos en Margarita de niebla (1927) del propio Torres Bodet: "La hora, como un globo de goma, había ido llenándose de oxígeno y los minutos se alargaban, elásticos, en las telas de araña del jardín” (en Ródenas, 2004: 335). Y más aún, en el siguiente texto se aprecian buena parte de las características de la novela lírica establecidas por Villanueva:

La señorita Millers no era sin embargo lo que se llama, en sociedad, una mujer hermosa y aun hubiera dudado, en la calle, en el teatro o en el tranvía de afirmar que fuese ya una mujer. En torno a sus movimientos se formaba ese vacío brusco que envuelve a los muy jóvenes, esperando, para desaparecer la plenitud del crecimiento que lo llene con el desarrollo de los cuerpos que rodea. Pero había, en su cabellera, no sé qué libertad parecida a la de la música, hecha también de una continuidad de ausencias, y en sus ojos, la suavidad se construía de muchas aristas interiores como sucede con el reflejo apaciguado de las esmeraldas. Más que blanca, su piel parecía violeta. (Ródenas, 2004: 336)

dejarnos el mayor número de tradiciones que contrariar. Sería declararnos vencidos querer persistir en los cauces de las ideas aceptadas por los hombres del ochocientos. Las obras producidas bajo el imperio del positivismo ortodoxo pudieron ser bellas. No les neguemos nuestra admiración, neguémosles nuestra obediencia” (1928: 7). 
La cita anterior revela que, hacia 1927, Jaime Torres Bodet era partidario de la construcción de la novela moderna basada en la intensidad poética. No obstante, muy poco después de la publicación de Margarita de niebla, debió haber iniciado un proceso de conocimiento mayor de Proust, hecho que le abrió la perspectiva y, de algún modo, le hizo ver el abuso que las artes habían cometido con la poesía y, en el caso particular de la novela, el debilitamiento de los personajes novelescos basados en la metáfora poética. Es lo que se desprende de sus "Reflexiones en torno a la novela", trabajo publicado en su libro de ensayos Contemporáneos, del que se desprende prácticamente una abdicación del mecanismo poético que venía realizando, la metáfora poética:

Todas las tendencias modernas de la poesía, de la pintura y del pensamiento han encontrado eco en la novela y han querido destruir su unidad esencial, imponiéndole un sello extraño. En tanto que el drama se hacía lírico en D’Annunzio, en Maeterlinck y en Lord Dunsany, la poesía - tan ajustada dentro de la estrecha túnica que le ciñeron las escuelas posteriores al simbolismo- se vaciaba toda en las novelas de Régnier, de Jammes y, más tarde, de Giraudoux y de Larbaud. El valor de la imagen se exagera hasta la viciosa delicia en estos autores. El refinamiento del estilo adelgaza el perfil de los caracteres y los viste apenas con ese lúcido encaje con que la espuma del mar cubre, sin borrarlo, el nombre que escribimos con el dedo en la arena de la orilla. (Torres Bodet, 1928: 17)

Debe recordarse que Torres Bodet declaró que, en principio, no conoció a profundidad al escritor francés porque lo consideraba difícil de abordar. La cercanía con Proust debió haberse generado a partir de que este escribiera El tiempo recobrado, último tomo de En busca del tiempo perdido, aparecido en París en 1927. Como se recordará, en las últimas cien páginas de este volumen, Proust, que desconfiaba de los críticos, incorporó su visión descriptiva de la poética empleada en su novela. Entre otros conceptos, aparecen allí dos de importancia para comprender la novela de Jaime Torres Bodet, Proserpina rescatada: la memoria involuntaria y la metáfora que, para diferenciarla de la caracterizada por Sheridan, llamaré metáfora narrativa. Una aproximación a la descripción de ambos conceptos se publicó en las páginas de la revista Contemporáneos en marzo de 1930 a poco más de un año de que Torres Bodet emigrara a Madrid en misión diplomática, en febrero de 1929. La nota fue escrita por Ramon Fernandez, en traducción de Xavier Villaurrutia:

Proust ha dado valor a un principio que debiera servir de base a toda estética futura. Este principio es el siguiente: los sucesos y los momentos de nuestra vida que más nos llegan al corazón, que nos dan el sentimiento de existir, no son transparentes y son difícilmente accesibles a la inteligencia, sobre todo en el instante en que lo vivimos. No obstante, para sentirnos vivir verdaderamente tenemos necesidad de poseer en espíritu lo que hemos vivido en la realidad. El arte nos da los medios de hacer interior al espíritu esta zona irracional por facultades como la memoria, por relaciones tales como la metáfora, que constituyen los equivalentes sensibles del pensamiento. (1930: 269)

Lo que Fernandez anotaba allí era justamente los conceptos de memoria y metáfora como fundamento de toda estética futura. El principio que Proust planteaba en El tiempo recobrado y en el libro póstumo, Contra Sainte-Beuve, de 1954, se fundamenta en que la inteligencia no es la que nos entrega el registro fiel de nuestra vida, sino la memoria, la memoria involuntaria. La sensación de cada hora o instante vivido queda cautiva en un objeto material. Es posible 
que perdamos muchos recuerdos allí atrapados, y solo unos cuantos puedan ser liberados, pero la resurrección depende del puro azar. Aunque voluntariamente nosotros decidamos colocar un recuerdo en un objeto, este no preservará la poesía que emana del involuntario a causa de que no es la inteligencia la que libera los recuerdos, sino, nuevamente, el azar. Proust pone varios ejemplos de memoria involuntaria, entre ellos, el más conocido, el de la magdalena y el té: cierto día, al regresar a casa, muerto de frío porque afuera está nevando, la cocinera le dio té con un trozo de pan. Al remojarlo lo invadieron colores, sabores y un estado de felicidad al recordar que de niño ingresaba a la habitación del abuelo, recién despertado, y este le daba aquel pedazo de pan remojado en té. Al llevárselo a la boca en el presente volvía a sentir ese momento de impresión pasada, "de vida pura conservada pura" (Proust, 2019: 4). En otras palabras, es la memoria involuntaria que, al liberar por azar un recuerdo de vida pura, la que genera la metáfora narrativa, la cual consiste en asociar dos realidades aparentemente irreconciliables, una presente con una del pasado para recuperar una parte de nuestro ser encerrada en el olvido. Esta es la manera en que Torres Bodet describió la metáfora narrativa en su libro de ensayos sobre Marcel Proust de un tardío 1967:

Esta metáfora no puede inventarla a su gusto la voluntad; no obedece a una lógica del recuerdo. Brota, al contrario, de una rendija abierta — quién sabe cómo- en el muro sólido del olvido. Pasamos y pasamos, durante días, durante meses, frente a ese muro, sin percatarnos de lo que esconde y de pronto, por una circunstancia fortuita, vemos que sale - de entre las piedras - un tembloroso rayo de luz. (1967: 41)

En otro lugar he realizado una lectura de Proserpina rescatada. ${ }^{6}$ Aquí solo apuntaré que Torres Bodet emplea esta metáfora narrativa en su novela para confrontar dos momentos en la vida de Dolores Jiménez, tanto en su carácter de personaje como en su carácter simbólico, con la finalidad de que, al contrastar el pasado con el presente pueda arrojarse un rayo de luz, sobre la sicología profunda del personaje y el tipo, los tipos de novela que ella simboliza: la realista y la de vanguardia. Durante sus estudios en la Facultad de Medicina, en la Ciudad de México, Dolores Jiménez es caracterizada con elementos de la novela realista, combatida por Torres Bodet en su texto de "Reflexiones sobre la novela", entre otros, el excesivo tiempo que tomaba para narrar una historia; en Nueva York, en su carácter de médium, con la vanguardia cosmopolita y destructora de aquella ciudad: Dolores tiene el mismo pulso que la urbe; asimismo, despierta en la madrugada a Delfino para que le cuente sus sueños, en franca alusión al surrealismo.

Que Jaime Torres Bodet, como ha afirmado Christopher Domínguez (1994: 231-232), conocía mejor la realidad novelesca y que sabía lo que quería, queda evidente en el siguiente párrafo en donde plantea su visión de la novela moderna, expresión, quizá de la moderación de su carácter: si la balanza se inclina hacia lo poético, la novela pierde interés; si lo abandona, carece de centro.

La novela, pues, en su realización más perfecta, es un género que no cabe dentro del clasicismo, que se aparta de él de un modo natural, por esencia; porque, en ella, la parte de interés que el asunto suscita domina demasiado al interés que la simple forma pudiera sugerir. En tanto que en la poesía lírica, en el ensayo y aun en la tragedia, es difícil señalar el límite

\footnotetext{
${ }^{6}$ Véase "La revelación de Proserpina" en En breve, la novela corta en México, (coord.) Anadeli Bencomo y Cecilia Eudave, 2014, 101-115. Disponible en línea: http://www.lanovelacorta.com./en-breve.html. [30/01/2020]
} 
preciso, el fiel en que alternan los platillos de la balanza, en la novela, el problema del estilo si no cesa - no puede cesar nunca en arte- cambia de centro. De una forma de expresión que era, se vuelve una forma de exploración. En la poesía, el estilo es una frontera; en la novela, un camino. (Torres Bodet, 1928: 18)

\section{Conclusión}

He querido mostrar con este par de ejemplos que estamos lejos aún de conocer los diversos mecanismos, y consecuentemente una poética, de la novela corta moderna mexicana. Si concluimos que una forma de la modernidad reside en la hibridez de género la situación se agudiza otro tanto, pues la novela corta muestra la gran variedad de recursos para construir su arquitectura: un cuadro, una foto, un poema, una metáfora-. Por otro lado, me parece que debemos continuar estudiando las novelas de cerca puesto que las generalidades sirven para ubicarlas, pero no para comprenderlas: la novela de Revolución no carece de elementos revolucionarios ni la revolucionaria de tradición.

\section{Bibliografía}

AVECHUCO CABRERA, Daniel (2017): "La revolución narrada desde los márgenes: representaciones anatómicas de la violencia en Cartucho, de Nellie Campobello". Literatura Mexicana XXVIII (1) (2017): 69-98. DOI: https://doi.org/10.19130/iifl.litmex.28.1.2017.977

BENJAMIN, Walter (2014): Baudelaire. Ed. José Manuel Cuesta Abad. Madrid, Abada Editores.

CASTRO LEAL, Antonio (1960): La novela de la Revolución mexicana. México, SEPAguilar, vol. II.

CAMPOBELlO, Nellie (1960): Mis libros. Compañía General de Ediciones, México.

--- (2016): Las manos de mamá. En su libro Obra reunida. $2^{\mathrm{a}}$ ed. México, Fondo de Cultura Económica.

CORRAL RIGAN, José (1924): "La influencia de la Revolución en nuestra literatura", El Universal Ilustrado, VIII (393) (20 de noviembre de 1924): 45.

DOMÍNGUEZ MICHAEL, Christopher (1994): “Los hijos de Ixión”. En Rafael Olea Franco y Anthony Stanton (eds.), Los contemporáneos en el laberinto de la crítica. México, El Colegio de México: 225- 236. DOI: https://doi.org/10.2307/j.ctv6jmwr3.27

ESCOBAR ARRONIS, José (1994): "Literatura de «Lo que pasa entre nosotros». La modernidad del costumbrismo". Berta Pallares et al. (eds.), Sin fronteras. Homenaje a María Josefa Canellada. Madrid, Editorial Complutense, 1994: 193-206.

FERNÁNDEZ, Ramón (1930): "Nota sobre la estética de Proust". Contemporáneos, 6 (22) (marzo de 1930): 269-279.

GARCÍA GUTIÉRREZ, Rosa (1999): Contemporáneos: la otra novela de la Revolución mexicana. Huelva, Universidad de Huelva.

JIMÉNEZ RUEDA, Julio (1924): "El afeminamiento en la literatura mexicana". El Universal, (2981) (21 de diciembre de 1924): 3. 
MONTERDE, Francisco (1924): "Existe una literatura mexicana viril". El Universal, (2985) (25 de diciembre de 1924): 3.

ORTUÑO SANDOVAL, Marcela (1998): "Un acercamiento interpretativo a Las manos de mamá de Nellie Campobello”. Semiosis. Nueva Época 1 (3-4) (enero-diciembre 1998): 126-137.

PARRA, Max (2017): "Usos literarios de la fotografía en Cartucho de Nellie Campobello". Mariano Azuela y la literatura de la Revolución Mexicana. México, El Colegio de México. DOI: https://doi.org/10.2307/j.ctt2204qmm.19

PRATT, Mary Louise (2004): "Mi cigarro, mi Singer, y la Revolución mexicana: la danza ciudadana de Nellie Campobello". Cuadernos Pagu 22 (2004): 151-184. DOI: https://doi.org/10.1590/s0104-83332004000100007

PROUST, Marcel (2019): La muerte de las catedrales. Greenbooks Editore, Roma.

PULIDO HERRÁEZ, Begoña (2011): “Cartucho, de Nellie Campobello: la percepción dislocada de la Revolución mexicana”. Latinoamérica 52 (1) (2011): 31-51.

RAMOS, Luis Arturo (2011): "Notas y claves para un ensayo sobre la novela corta en México". Una selva tan infinita. La novela corta en México (1872-2011). México, UNAM, 2011.

RÓDENAS DE MOYA, Domingo, ed. lit. (2004): Contemporáneos. Prosa. Madrid, Fundación Santander Central Hispano.

SHERIDAN, Guillermo (1982): Homenaje nacional a los Contemporáneos. Monólogos en espiral. Antología de narrativa. México, Instituto Nacional de Bellas Artes / Secretaría de Educación Pública.

SHERIDAN, Guillermo (1985): Los Contemporáneos ayer. México, Fondo de Cultura Económica.

TORRES BODET, Jaime (1928): Contemporáneos. Notas de crítica. México, Herrero.

--- (1967): Tiempo y memoria en la obra de Proust. México, Porrúa.

VILLANUEVA, Darío (2009): "La novela lírica de Francisco de Umbral”. Francisco de Umbral y su tiempo. Valladolid, Ayuntamiento de Valladolid-Fundación Francisco de Umbral.

WEIMER, Tanya (2010): “Las imágenes barajadas en Cartucho de Nellie Campobello". Cuadernos Americanos 134 (4) (2010): 103-23.

(C) Gabriel M. Enríquez Hernández

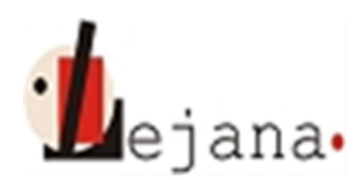

http://ojs.elte.hu/index.php/lejana

Universidad Eötvös Loránd, Departamento de Español, 1088 Budapest, Múzeum krt. 4/C 